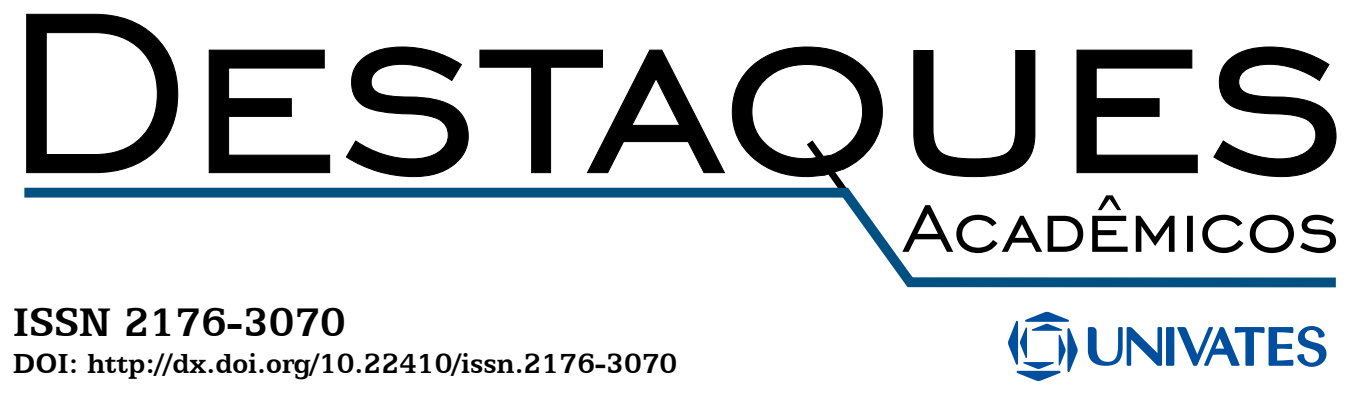

\title{
CIÊNCIAS HUMANAS E SOCIAIS
}

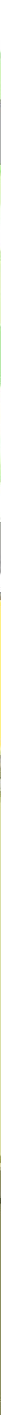




\section{(1) \\ UNIVATES}

Universidade do Vale do Taquari - Univates

Reitor: Prof. Me. Ney José Lazzari

Vice-Reitor e Presidente da Fuvates: Prof. Dr. Carlos Cândido da Silva Cyrne

Pró-Reitora de Pesquisa, Extensão e Pós-Graduação: Profa. Dra. Maria Madalena Dullius

Pró-Reitor de Ensino: Profa. Dra. Fernanda Storck Pinheiro

Pró-Reitora de Desenvolvimento Institucional: Profa. Dra. Júlia Elisabete Barden

Pró-Reitor Administrativo: Prof. Me. Oto Roberto Moerschbaecher

Coordenação: Ana Paula Lisboa Monteiro

\section{AINITATESS}

Editoração: Glauber Röhrig e Marlon Alceu Cristófoli

\section{Conselho Editorial da Editora Univates}

\section{Titulares}

Fernanda Rocha da Trindade

Marli Terezinha Quartieri

Rogério José Schuck

Fernanda Cristina Wiebusch Sindelar

\author{
Suplentes \\ Adriane Pozzobon \\ Ieda Maria Giongo \\ João Miguel Back \\ Alexandre André Feil
}

Avelino Talini, 171 - Bairro Universitário - Lajeado - RS - Brasil

Fone: (51) 3714-7024 / Fone/Fax: (51) 3714-7000

editora@univates.br / http://www.univates.br/editora

D476 Destaques Acadêmicos / Centro Universitário Univates - Vol. 1, no. 1 (2009) - Lajeado, RS: Ed. da Univates, 2018.

v. 10, n. 2, 2018.

Instituição mudou o nome para Universidade do Vale do Taquari - Univates em 2017.

Trimestral

ISSN 2176-3070

1. Ensino. 2. Ensino multidisciplinar. I. Universidade do Vale do Taquari - Univates.

CDU: 378

Catalogação na publicação - Biblioteca da Univates

Bibliotecária Andrieli Mara Lanferdini - CRB 10/2279

Os artigos são de exclusiva responsabilidade do(s) autor(es).

(C) Fundação Vale do Taquari de Educação e Desenvolvimento Social - FUVATES 


\section{DESTAQUES}

Conselho Editorial da Revista

Cristiane Antonia Hauschild

Giselda Veronice Hahn

João Miguel Back

Marlon Dalmoro

\section{Coordenador desta edição}

João Miguel Back

Pareceristas desta edição

Edson Moacir Ahlert

Elisabete Cristina Barreto Muller

Fernanda Marders

Letícia Regina Konrad

Maribel Girelli

Rosmari Terezinha Cazarotto

Sandro Fröhlich

Sérgio Nunes Lopes

Tania Micheline Miorando

Thaís Carnieletto Müller 


\section{APRESENTAÇÃO}

Com o objetivo de compartilhar conhecimentos e socializar olhares e saberes, sobre diversos temas e áreas de conhecimento, essa obra cumpre um papel importante na fomentação e divulgação de estudos e pesquisa pertinentes ao universo acadêmico.

As reflexões transitam entre várias áreas de saber, como área Jurídica, Humanas, Pedagogia, Ensino, Metodologia, Gênero e outros. Apresentam estudos de questões importantes em cada área, e ainda nos provocam com temas transversais, que exigem abertura de olhares e percepções para a complexidade da realidade atual e futura, frente aos desafios cada vez mais relevantes e urgentes, considerando o mundo em constantes mudanças e sedento de novas compreensões e propostas de solução, para seus problemas emergentes.

O homem contemporâneo vê-se frente a um mundo dinâmico, tomado pelas tecnologias que avançam em larga escala, mas carente de uma cultura de diálogo que consiga refletir sobre os rumos da ciência e do saber, resgatando seu papel ético fundamental, que é o de proporcionar um bem estar para todos os seres humanos, com o foco na inclusão social e enfrentamento das necessidades mais prementes que assolam grande parte da população nacional e mundial. $\mathrm{O}$ saber, sobretudo, alicerçado em pressupostos éticos, pode ser uma ferramenta fundamental para prospectar mais esperança de um mundo melhor para todos.

Essa obra pretende contribuir no diálogo entre pessoas e áreas de saber, e incentivar a todos a se voltarem para os desafios do universo que nos envolve, sendo ele mais próximo ou longínquo. Todos têm um papel a cumprir. Boas leituras e reflexões a todos!

Prof. Dr. João Miguel Back

Coordenador desta edição 


\section{SUMÁRIO}

A MORFOLOGIA DO RESUMO E DA INTRODUÇÃO NOS TRABALHOS CIENTIIFICOS EM CONSONÂNCIA COM AS NORMAS DA ASSOCIAÇÃO BRASILEIRA DE NORMAS TÉCNICAS. 6

Henrique Rosmaninho Alves

A DELIMITAÇÃO DO ESPAÇO RURAL EM PORTO ALEGRE:

TERRITÓRIO, REGIÃO E DESENVOLVIMENTO 16

Melissa Heberle, Luciana Turatti, Júlia Elisabete Barden

A CORPOREIDADE NOS ANOS INICIAIS DO ENSINO

FUNDAMENTAL: REFLEXÕES A PARTIR DE UMA PRÁTICA DE JUST

DANCE.

Mateus Lorenzon, Leandro Oliveira Rocha

O TESTAMENTO VITAL DIANTE DO DIREITO À VIDA 34

Bruna Cardoso, Beatris Francisca Chemin

DOS CRIMES DE LAVAGEM DE DINHEIRO - LEI N. ${ }^{\circ}$ 9.613/98: UMA

ANÁLISE A PARTIR DA LEGISLAÇÃO VIGENTE.

Cláudia Daniela Behrens, Marina Cassol Oliveira, Pauline Von Mühlen

DA CORREIÇÃO PARCIAL: CONSIDERAÇÕES DOUTRINÁRIAS E JURISPRUDENCIAIS

Cláudia Daniela Behrens

A JUDICIALIZAÇÃO DAS POLÍTICAS PÚBLICAS NO BRASIL SOB A PERSPECTIVA DA SEPARAÇÃO DE PODERES, RESERVA DO POSSÍVEL E DO MÍNIMO EXISTENCIAL

Pablo Florentino Fróes Couto

QUANDO MIGRAR É NECESSÁRIO: AÇORIANOS POVOAM O CONTINENTE DE RIO GRANDE DE SÃO PEDRO (MEADOS DO SÉCULO XVIII). 104

Cibele Caroline da Rosa, Luís Fernando da Silva Laroque

A AUSÊNCIA DA MULHER NO ENSINO DE HISTÓRIA 117

Érica Brites da Silva Fófano, Jussara Maria Tostes dos Santos Garcia, Clodoaldo Sanches

Fófano, Paulo Jonas dos Santos Júnior 